\title{
ROMANIAN
}

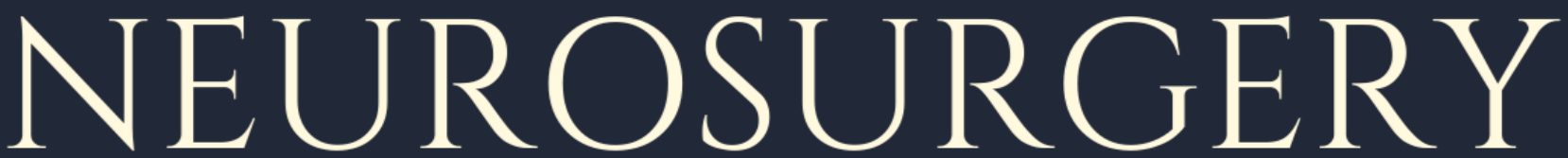

\author{
Vol. XXXIV | No. $1 \quad$ March 2020
}

\section{Clinical spectrum of paediatric head injury. A prospective study from tribal region}

\author{
Krishna Govind Lodha, \\ Tarun Kumar Gupta, \\ Gaurav Jaiswal, \\ Yogendra Singh
}




\title{
Clinical spectrum of paediatric head injury. A prospective study from tribal region
}

\author{
Krishna Govind Lodha, Tarun Kumar Gupta, Gaurav Jaiswal, \\ Yogendra Singh
}

RNT Medical College Udaipur, Rajasthan, INDIA

\begin{abstract}
Introduction: Traumatic brain injury is considered as a major health problem which causes frequent deaths and disabilities in the paediatric population with special concern to tribal regions of developing countries like India where aetiology of traumatic brain injury in the paediatric population fall from height dominant over the road traffic accident as a major.
\end{abstract}

Aim \& Objective: The aim is to analyse the epidemiology, mechanism, clinical presentation, severity and outcome of paediatric head injury in the tribal region of northern India that could help to make preventive policies to improve their care.

Material Methods: It is a prospective observational study of 345 children of up to 18 years of age admitted under Department of Neurosurgery from October 2017 to April 2019.

Results: The study population comprised of 345 paediatric patients. Mean age was 9.25 years.36.81\% patients were in 1-6-year age group and male to female ratio was 2.45. The most common cause for trauma was fall from height in 179(52\%) cases followed by RTA in $141(41 \%)$ cases. The most common radiological finding was depressed skull fractures in $97(50 \%)$ cases. There was 35\% mortality in severe head injury patients.

Conclusion: This study through some light on the different scenario of head injury in Tribal regions of Developing country and will help to formulate effective strategies for prevention and better care of the patients.

\section{INTRODUCTION}

Traumatic brain injury (TBI) is a leading cause of death and disability in children worldwide. [1] Young children are at relatively high risk of minimal and mild traumatic head injuries. An increase in the more severe and fatal traumatic brain injuries has been found in late adolescence. Pediatric TBI has different Pathophysiology due to higher vascularity, plasticity and less rigidity of scalp .pediatric brain has less degree of myelination which related to brain capacity to absorption of traumatic forces and increase the susceptibility to TBI.[2] TBI is classified as mild (Glasgow Coma Scale [GCS] 13-15), moderate (GCS 9-12), or severe (GCS 3-8).[3]

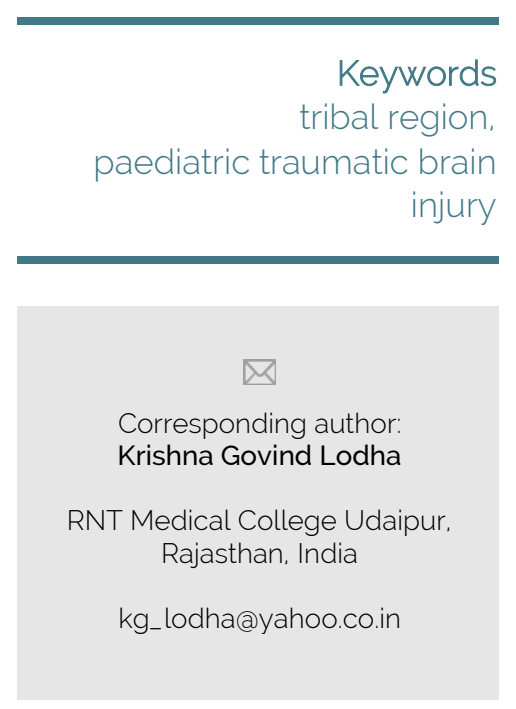

Copyright and usage. This is an Open Access article distributed under the terms of the Creative commons Attribution Non-Commercial No Commons Attribution Non-Commercial No
Derivatives License (https://creativecommons org/licenses/by-nc-nd/4.0/) which permits noncommercial re-use, distribution, and reproduction in any medium, provided the original work is unaltered and is properly cited.

The written permission of the Romanian Society of Neurosurgery must be obtained for commercial re-use or in order to create a derivative work.

ISSN online 2344-4959 (C) Romanian Society of Neurosurgery

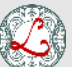

First published March 2020 by London Academic Publishing www.lapub.co.uk 
The study focuses on understanding the etiology, clinical presentation, treatment options, and outcome of these patients with special concern to tribal regions of developing countries like India where fall from height dominant over the road traffic accident as a major etiology of traumatic brain injury in paediatric population.[4] Thus there is a critical need for effective fall and traffic accidents prevention strategies for children, and we should give attention to the predicting factors for more effective care of such patients

\section{MATERIAL METHODS}

It is a prospective observational study of 345 children of upto 18 years of age admitted under Department of Neurosurgery from October 2017 to April 2019. Study was started after obtaining the permission from ethical committee of the hospital. Informed consent was obtained from the parent / guardian / relative of the patient. A detailed clinical history obtained from the parents/guardian/relative admitted in the hospital with head injury.

\section{ANALYSIS}

Statistical analysis was performed using the collected data on incidence and clinical- radiologic correlation. Analyses included the age and gender distribution of the Children, the cause and location of the injury, medical status, and the part of the head injured and type of injury and the treatment provided. A comparison of types of head injuries sustained by gender, age, and cause was also carried out.

\section{RESULTS}

The study population comprised of 345 paediatric patients aged Between 2 month to 18 years with a mean age of 9.25 years. There was 245 males (71.01\%) and 100 females (28.98\%) with male to female ratio of 2.45:1.

Table 1. Outcome according to age

\begin{tabular}{|l|l|l|l|l|l|l|}
\hline Age & No & $\%$ & Male & Female & Good outcome & Poor outcome \\
\hline$<1 \mathrm{yr}$ & 24 & 6.95 & 14 & 10 & $18(75 \%)$ & $6(25 \%)$ \\
\hline $1-6 y r s$ & 127 & 36.81 & 95 & 32 & $108(85.03 \%)$ & $19(14.07 \%)$ \\
\hline 7-12yrs & 120 & 34.78 & 84 & 36 & $110(91.7 \%)$ & $10(8.3 \%)$ \\
\hline 13-18yrs & 74 & 21.44 & 52 & 22 & $62(83.8 \%)$ & $12(16.2 \%)$ \\
\hline TOTAL & 345 & $100 \%$ & $245(71.1 \%)$ & $100(28.9 \%)$ & 298 & 47 \\
\hline
\end{tabular}

The most common cause for trauma was fall from height in 179(52\%) cases followed by RTA in 141(41\%) cases, Bull horns in 11 (3\%) cases; assault 7 (2\%) cases.

Table 2. Mode of injury

\begin{tabular}{|l|l|l|l|l|l|}
\hline Mechanism & No & $\%$ & Mild & Moderate & Sever \\
\hline Fall & 179 & 52 & $93(52 \%)$ & $73(41 \%)$ & $13(7 \%)$ \\
\hline RTA & 141 & 41 & $38(27 \%)$ & $72(51 \%)$ & $31(22 \%)$ \\
\hline Assault & 7 & 2 & $5(72 \%)$ & $1(14 \%)$ & $1(14 \%)$ \\
\hline Sport & 7 & 2 & $7(100 \%)$ & & \\
\hline Bull horn & 11 & $3 \%$ & $8(73 \%)$ & $2(18 \%)$ & $1(10 \%)$ \\
\hline
\end{tabular}

RTA: Road traffic accident

Severity of injury was decided with GCS score at the time of admission and it was mild injury in 218 (63.19\%), moderate in 92 (26.67\%) and sever in 35 (10.14\%) cases. Outcome of injury was good in mild head injury group and poor outcome was associated with severe head injury group.

Table 3. Severity and outcome

\begin{tabular}{|l|l|l|l|l|l|}
\hline GCS & Severity & No & Good outcome & Poor outcome & Mortality \\
\hline $13-15$ & Mild & 218 & $210(96.33 \%)$ & $8(3.67 \%)$ & None \\
\hline
\end{tabular}




\begin{tabular}{|l|l|l|l|l|l|}
\hline $9-12$ & Moderate & 92 & $60(65.22 \%)$ & $22(23.91 \%)$ & $10(10.87 \%)$ \\
\hline $3-8$ & sever & 35 & $9(25.71 \%)$ & $15(42.86 \%)$ & $11(31.43 \%)$ \\
\hline
\end{tabular}

CT scan findings were positive in 195 cases and it was normal in 150 cases. Most common radiological finding was Depressed skull fractures in 97(50\%) cases, Extradural hematoma in 29 (15\%), Subdural hematoma in 20 (10\%), contusion in 23 (12\%), ICH in 6 (3\%), IVH in 2 (1\%) cases. (Figure-1 and 2)

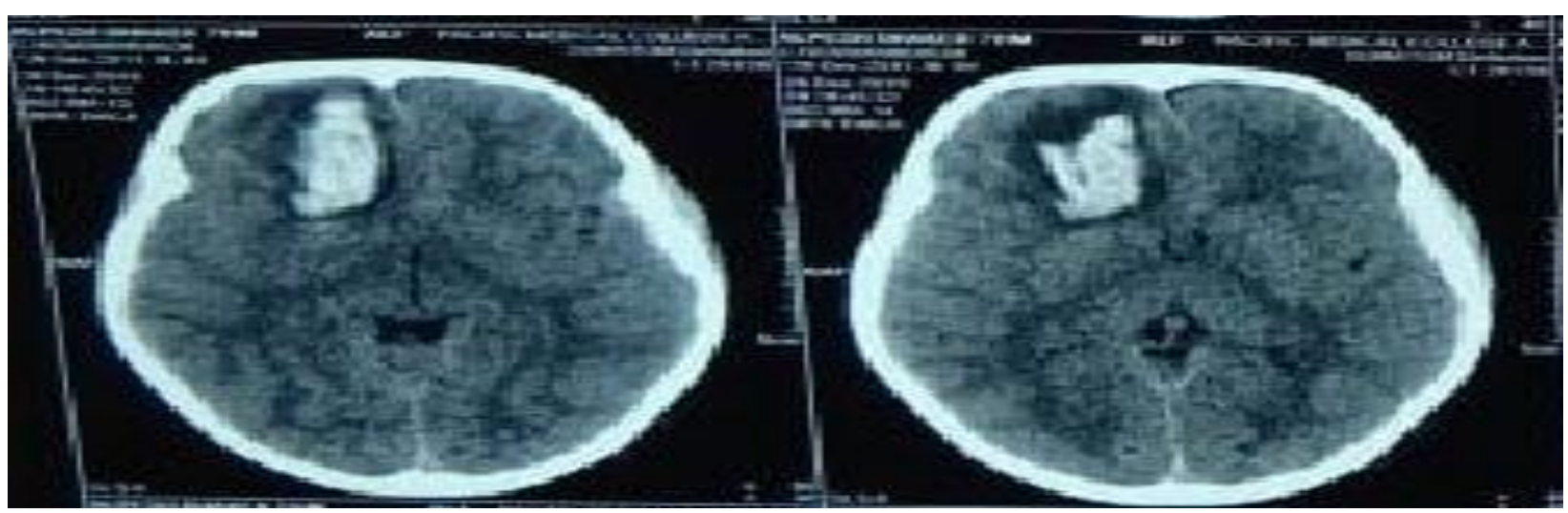

Figure 1. NCCT Head of 8 yrs old child admitted with h/o of fall from roof with GCS E2V3M5 Pupils b/l 3mm reacting to light.

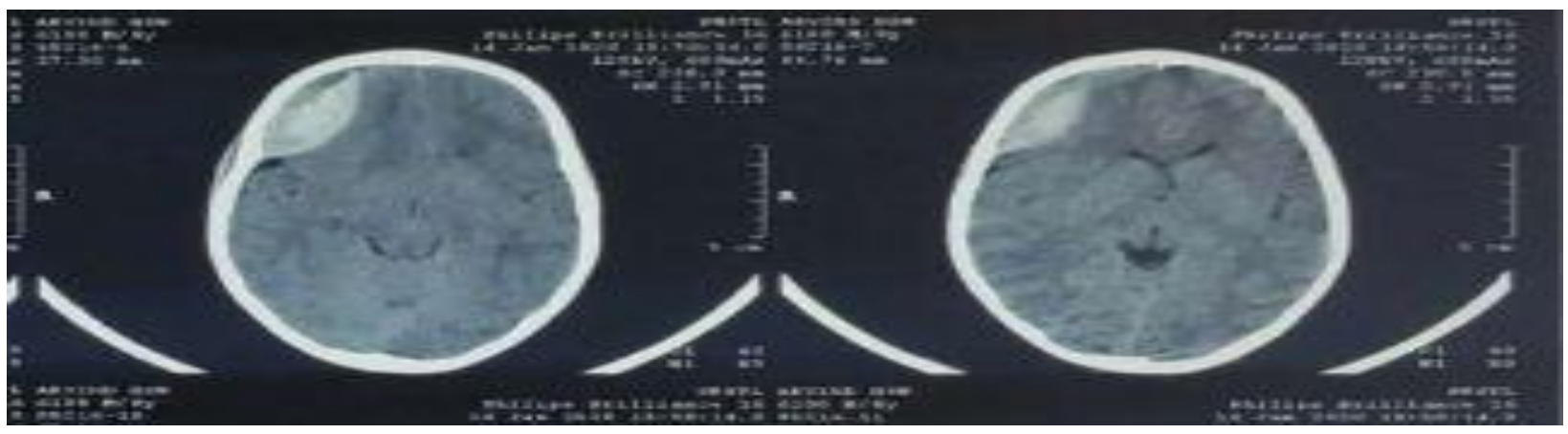

Figure 2. NCCT Head of 6 yrs male child admitted with h/o fall from tree and GCS at admission E4V3M3, Pupils b/l 3 mm reacting, after evacuation of EDH Child improved and at time of discharge GCS was E4V5M6.

Table 4. Radiology positive in 195 cases and negative in 150 cases

\begin{tabular}{|l|l|l|l|l|}
\hline CT Finding & No & $\%$ & Surgery & Conservative \\
\hline Skull fractures & 97 & $50 \%$ & 40 & 57 \\
\hline EDH & 29 & $15 \%$ & 10 & 19 \\
\hline SDH & 20 & $10 \%$ & 8 & 12 \\
\hline Contusions & 23 & $12 \%$ & 11 & 12 \\
\hline ICH & 6 & $3 \%$ & 2 & 4 \\
\hline IVH & 2 & $1 \%$ & 0 & 2 \\
\hline Edema & 18 & $9 \%$ & 0 & 18 \\
\hline Total & 195 & $100 \%$ & 71 & 124 \\
\hline
\end{tabular}

EDH: Extradural Hematoma, SDH: Subdural Hematoma, ICH: Intracerebral Hematoma, IVH: Intra ventricular Hematoma

Out of 195 patients 71 patients' required surgery and rest 124 patients were managed conservatively. Fracture debridement or elevation done in 40 patients, Hematoma $(\mathrm{EDH}+\mathrm{ICH})$ evacuation was done in 12 patients, Contusectomy done in 11 patients and decompressive craniectomy done in 8 patients. (Figure 3 and 4). 


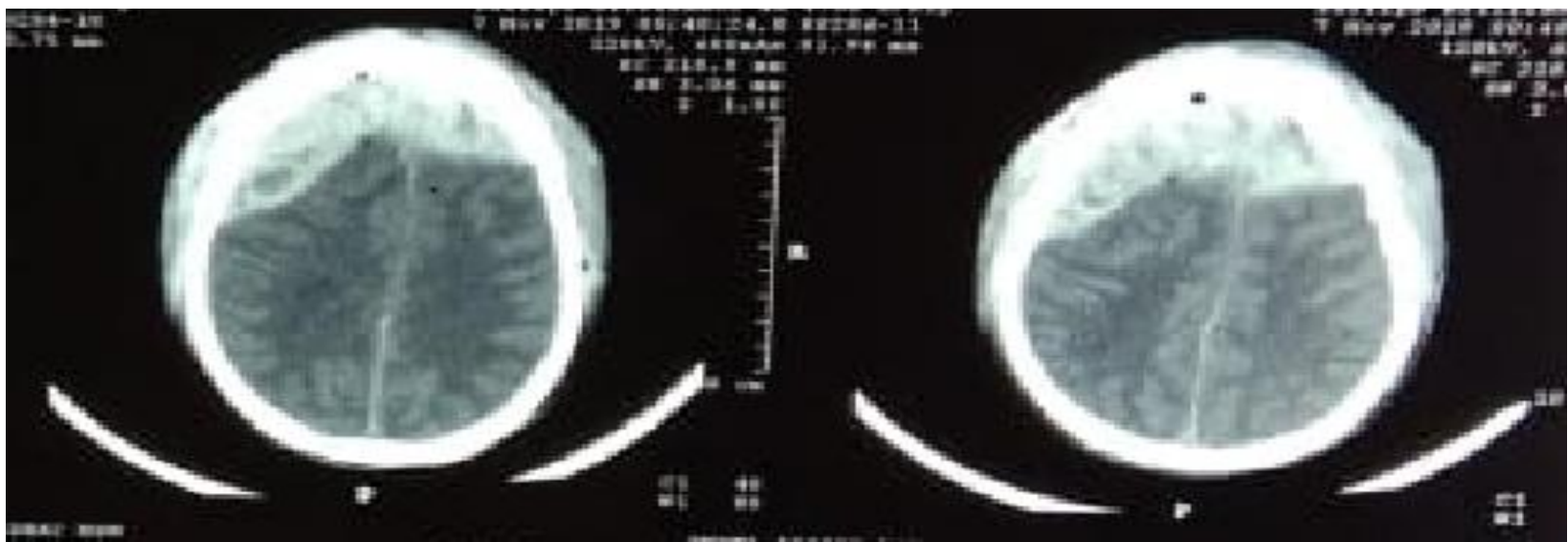

Figure 3 (a). NCCT Head of 15yrs male admitted with h/o RTA with GCS E2V1M4 Pupils b/l 3mm reacting to light undergone bifrontal craniectomy with evacuation of EHD. He discharged with GCS E4V5M6 and under gone 3D Mold customized cranioplasty after 4 months.

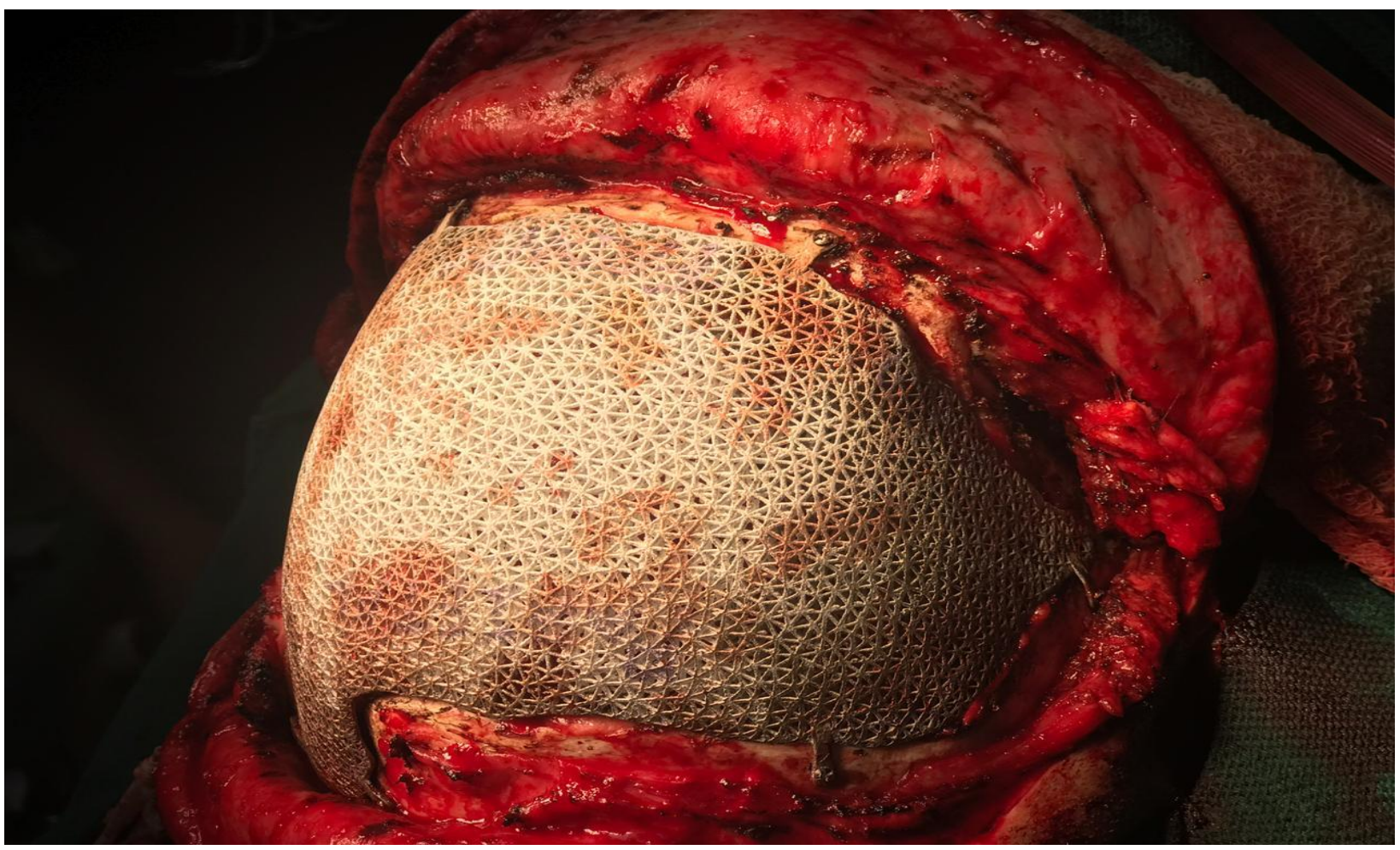

Figure 3 (b). Intraoperative photograph of 3D customised cranioplasty flap of above mentioned patient.

Table 5. Intervention and outcome

\begin{tabular}{|l|l|l|l|}
\hline Intervention & Total & Good outcome & Poor outcome \\
\hline Hematoma evacuation & $10(\mathrm{EDH})+2(\mathrm{ICH})$ & $10(83.33 \%)$ & $2(16.67 \%)$ \\
\hline Contusectomy & 11 & $5(45.4 \%)$ & $6(54.5 \%)$ \\
\hline Decompressive craniectomy & 8 & $3(37.5 \%)$ & $5(62.5 \%)$ \\
\hline $\begin{array}{l}\text { Fracture debridement or } \\
\text { elevation }\end{array}$ & 40 & $35(87.5 \%)$ & $5(12.5 \%)$ \\
\hline Total & 71 & $53(74.65 \%)$ & $18(25.35 \%)$ \\
\hline
\end{tabular}

EDH: Extradural Hematoma, ICH: intracerebral Hematoma 
While doing the survey for associated injuries, out of 345 patients 105 patients have associated injuries and most common associated injury was facial injury in 42 patients followed by long bone fracture in 24 patients, chest injury in 10 patients, multiple injury in 16 patients, spinal injury in 8 patients and abdominal injury in 5 patients.

Table 6. Intervention and outcome

\begin{tabular}{|l|l|l|l|}
\hline Associated injury & Good outcome & Poor outcome & Total \\
\hline Nil & $226(94.17 \%)$ & $14(5.83 \%)$ & 240 \\
\hline Facial injury & $38(90.48 \%)$ & $4(9.52 \%)$ & 42 \\
\hline Limb fracture & $22(91.67 \%)$ & $2(8.33 \%)$ & 24 \\
\hline Spinal injury & $5(62.5 \%)$ & $3(37.5 \%)$ & 8 \\
\hline Chest injury & $8(80 \%)$ & $2(20 \%)$ & 10 \\
\hline Abdominal injury & $4(80 \%)$ & $1(20 \%)$ & 5 \\
\hline Multiple injuries & & $2(12.5 \%)$ & 16 \\
\hline Total & $14(87.5 \%)$ & & 345 \\
\hline
\end{tabular}

\section{DISCUSSION}

In India children below 18 years of age constitute about $40 \%$ of the total population [5]. Traumatic brain injury is listed as one of the most Comman cause of death in pediatric population. Our study on pediatric head injuries show male preponderance which also conformed in various studies [6].

In our study fall from height 179(52\%) was the most Comman cause of pediatric head injury [7]. This peculiarly occure due to fall from tree, unguarded rooftop while playing. This was followed by RTA 141 $(41 \%)$, bull horn $11(3 \%)$, assault $7(2 \%)$ and sport related injury 7 (2\%) [8].

Initial GCS score was the single most important factor affecting the out-come as described by Beca et [9].

The patient who had a GCS of 13-15 (218) had a poor out come in 8 (3.67\%), followed by GCS of 9-12 (92) who had a poor outcome in 22(23.91\%) followed be GCS of 8 or less then 8 (35) who had poor outcome in $15(42.86 \%)$ which is similar as reported by Astrand R et.al [10].

Out of 345 patients in our study, CT scan findings were positive in 195 cases and it was normal study in 150 cases. We found isolated skull bone fracture as most Comman CT findings in 97 (50\%) cases, it was associated with good outcome (87.5\%) similar results were described by Suresh et al [11]. Hematoma evacuation $(\mathrm{EDH}, \mathrm{ICH})$ was associated with good outcome in $83.3 \%$ and poor outcome in $16.67 \%$, contusion was associated in good outcome in $45.4 \%$ and poor outcome in $54.6 \%$ cases and decompressive craniectomy was associated with poor outcome in $62.5 \%$ cases. Tomberg et al also found the similar outcome in their study [12].

In our study, we found that $69.6 \%$ patient have isolated head injury with good outcome in $94.17 \%$ patient. Facial injury was seen in $12.17 \%$, limb fracture in $7 \%$, spinal injury in $2.3 \%$, chest injury in $3 \%$, abdominal injury in $1.5 \%$ and multiple injuries seen in $4.6 \%$ patients. Paret et al reported chest trauma in (62\%), limb fracture in (32\%), facial injury in (20\%), and multiple injuries in (48\%) cases. This difference is because we include all the Childers in our study irrespective to severity of the injury while author include only sever cases of head injury in peadtric patient [13].

The overall outcome in our study was death in $21(6.09 \%)$, vegetative state in $10(2.90 \%)$, severe disability in 12(3.48\%) and good outcome in $279(80.86 \%)$ of the cases which was similar to study conducted by Abrar Ahad Wani et al [14].

Table 7. Glasgow outcome scale

\begin{tabular}{|l|l|}
\hline GOS & N (\%) \\
\hline $\begin{array}{l}\text { Death (1) } \\
\text { Vegetative (2) }\end{array}$ & $21(6.09 \%)$ \\
Sever disability (3) & $10(2.9 \%)$ \\
Moderate disability (4) & $23(6.67 \%)$ \\
Normal (5) & $12(3.48 \%)$ \\
& $279(80.86 \%)$ \\
\hline
\end{tabular}

GOS: Glasgow Outcome Scale 


\section{CONCLUSION}

Conclusion: Our study highlights the different scenario of pediatric head injury in Tribal regions of Developing country, where even the minor head injuries are referred to tertiary care hospitals which can be easily managed by treating physicians. The findings of our study have implications for development of public health policy with especial reference to tribal regions of developing country. Where more than half of pediatric head injury which are minor in nature can be prevented by just increasing public awareness.

Financial support and sponsorship: Nil

Conflicts of interest: There are no conflicts of interest

\section{REFERENCES}

1. Jagannathan J, Okonkwo DO, Yeoh HK, Dumont AS, Saulle D, Haizlip J, et al.Long term outcomes and prognostic factors in pediatric patients with severe traumatic brain injury and elevated intracranial pressure. J Neurosurg Paediatr. 2008; 2:237-9. [Pub Med: 18831656]

2. Goldsmith W, Plunkett J: A biomechanical analysis of the causes of traumatic brain injury in infants and children. Am J Forensic Med Pathol 25: 89-100, 2004

3. Jennet B. Epidemiology of head injury. Arch Dis Child 1998; 78:403-6

4. Adirim TA, Wright JL, Lee E, Lomax TA, Chamberlain JM. Injury surveillance in a pediatric emergency department. Am J Emerg Med. 1999; 17:499-503. [Pub Med: 10530522]

5. International Institute for Population Studies. Mumbai, India: NF, India; 1998-9.
6. Mahapatra AK. Head injury in children. In: Mahapatra AK, Kamal R, Editors. A Text Book of Head Injury. Delhi: Modern Publication; 2004.p. 156-70.

7. Sambasivan M. Epidemeology-Pediatric head injuries. Neurol India 1995; 43:57-8.

8. Osmond MH, Brennan-Barnes M, Shephard AL. A 4-year review of Severe pediatric trauma in Eastern Ontario: $A$ descriptive analysis.J Trauma 2002; $\quad$ 52:8-12.Beca J, Cox PN, Taylor MJ, Bohn D, Butt W, Logan WJ, et al.

9. Somatosensory evoked potentials for Prediction of outcome in acute severe brain injury. J Pediatr. 1995; 126:44-9. [Pub Med: 7815222]

10. Astrand R, Undén J, Hesselgard $K$, Reinstrup $P$, and Romner B. Clinical factors associated with intracranial complications after pediatric traumatic head injury: An observational study of children submitted to a neurosurgical referral unit. Pediatr Neurosurg. 2010; 46:101-9. [Pub Med: 20664236]

11. Suresh HS, Praharaj SS, Indira Devi B, Shukla D, Sastry Kolluri VR. Prognosis in children with head Injury: An analysis of 340 patients. Neurol India. 2003; 51:16-8. [Pub Med: 12865508]

12. Tomber g T, Rink U, Tikk A. Computerized tomography and prognosis in pediatric head injury. Acta Neurochir (Wien) 1996; 138:543-48.

13. Paret G, Ben Abraham R, Berman S, Vardi A, Harel R, Manisterski $Y$, et al. Head injuries in children - Clinical characteristics as prognostic factors. Harefuah. 1999; 136:677-81. 755. [PubMed: 10955086]

14. Abrar Ahad Wani, Arif Hussain Sarmast, Muzaffar Ahangar pediatric head injury: A study of 403 cases in a tertiary care hospital in a developing country. J Pediatr Neurosci. 2017 Oct-Dec; 12(4): 332-337.doi: 10.4103/JPN_80_17. 